\title{
Technology on Frequency Tracking Study of High-frequency Induction Heating Power
}

\author{
Jun Zhou ${ }^{1, a}$, \\ ${ }^{1}$ Electrical Engineering College of Northeast Dianli \\ University , \\ Jilin, Jilin, China, 132012 \\ ajizhoujun@126.com
}

\author{
Yemao Zhang*2,b \\ ${ }^{2}$ Electrical Engineering College of Northeast Dianli \\ University, \\ Jilin, Jilin, China, 132012 \\ b3552664@163.com
}

\begin{abstract}
For the current full-bridge series with the load-frequency induction heating power of the resonant frequency automatic tracking problems, analysis of the series resonant inverter load waveform changes in the work process, this paper designed a whole based on the frequency tracking circuit analog circuit, the device chosen is simple, fast frequency adaptive. Finally, the simulation results by commissioning theoretical analysis and field experimental prototype was validated, the results prove the rationality of design.
\end{abstract}

Keywords-induction heating; waveform changes; frequency tracking; analog circuits

\section{INTRODUCTION}

Full-bridge type load resonant inverter series, when the working frequency of the resonant frequency near, sine wave at the output will be operating current, in the process of induction heating power supply due to load material, temperature changes and other factors, equivalent parameters of the load and the natural resonance frequency changes. the inverter always work in the power factor close to or equal to the quasi-resonant or resonant state 1 , in order to achieve zero-current or zero voltage switching. This requires adaptation to increase the range of induction heating power supply to the load, and improve the utilization of various types of load material, power frequency automatic tracking[1].

\section{POWER FREQUENCY TRACKING CIRCUIT}

\section{A. Work Process Analysis}

Full-bridge series with the load-frequency induction heating power inverter circuit shown in Figure 1, alternating current through the rectifier bridge rectifier, after filtered by the capacitor $\mathrm{DC}$ voltage $\mathrm{U}_{\mathrm{dc}}$ of about $300 \mathrm{~V}$, inverter circuit has four switches, four anti-parallel diodes, Voltage $\mathrm{U}_{\mathrm{AB}}$ at the output, $\mathrm{L}, \mathrm{R}$ are the equivalent inductance and equivalent resistance of load, resonant capacitor $\mathrm{C}$ are connected in series, RLC composed of series resonant circuit, $\mathrm{K}$ is a current transformer.

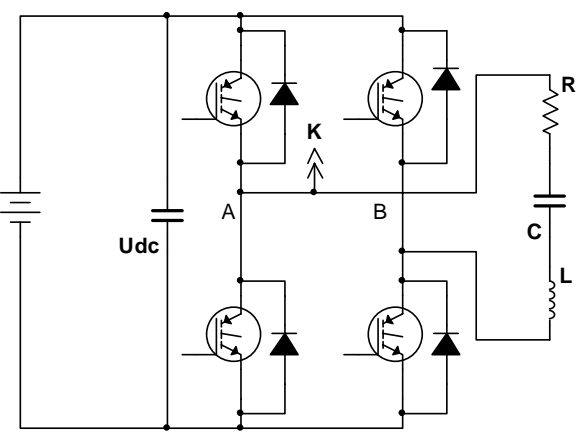

Figure1 .Full-bridge series resonant load inverter main circuit

When the high-frequency power supply is working properly, the driver circuit output frequency is $25 \mathrm{KHz}$, $50 \%$ duty cycle of the drive signal in Figure 2, in this case the resonant sine wave current signal obtained at the output of the inverter, in series in the circuit for sampling a current transformer $\mathrm{K}$, sampling the waveform in Figure 3 . because the sampling signal of current level is $\mathrm{mA}$, and can not be directly applied to the circuit, it is necessary to analyze the frequency of the signal input to the circuit shown in Figure 4, $\mathrm{L}_{1}$ and $\mathrm{L}_{2}$. this circuit is composed of the first half of the differential amplifier circuit by LM358, can effectively curb the zero drift, increasing the common-mode rejection ratio, effectively amplifying the input signal. Its magnification is

$A_{\mathrm{u}}=\frac{R_{5}}{R_{2}}$

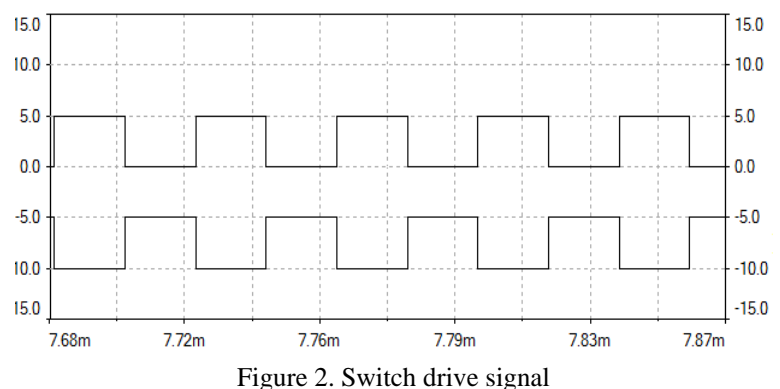

Figure 2. Switch drive signal 


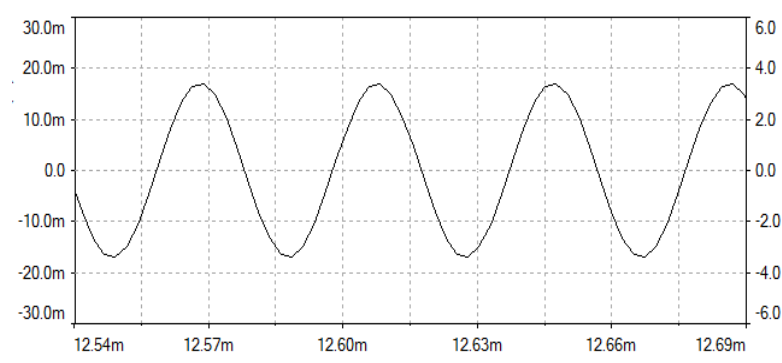

Figure 3. Sampling the current waveform of the inverter output

Since the differential amplifier circuit can handle only a voltage signal, the current signal obtained needs to be converted to a voltage signal, the Figure 4 for the sampling resistor. The current signal into a voltage signal input to the amplifying circuit[2].

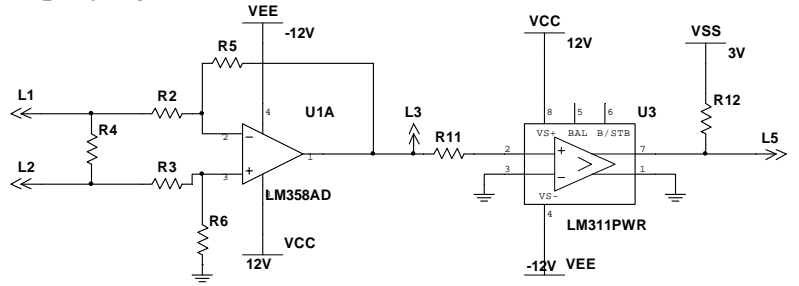

Figure 4. Frequency analysis circuit

LM311 composed of the second half of the voltage comparator, its non-inverting input to join an AC signal. When the AC signal crossing voltage zero into the positive half cycle, the output voltage will reach the positive supply voltage. When the AC signal crossing voltage zero into the negative half cycle, the output voltage will reach the negative supply voltage. LM311 is OTC (open collector) output, then a pull-up resistor $\mathrm{R}_{12}$ to high. Thus, as long as an output is low, then the result is the low. Obtained from the differential amplifying circuit amplifying the sine wave input to the back of the voltage comparator LM311. When a sine wave into the positive half cycle, the output voltage will be positive. When entering the negative half cycle, the output will be a voltage that is negative 0 ,in Figure 5 . The square wave in Figure 5 through L5 back to the control system microcontroller, the microcontroller can analysis resonant frequency.

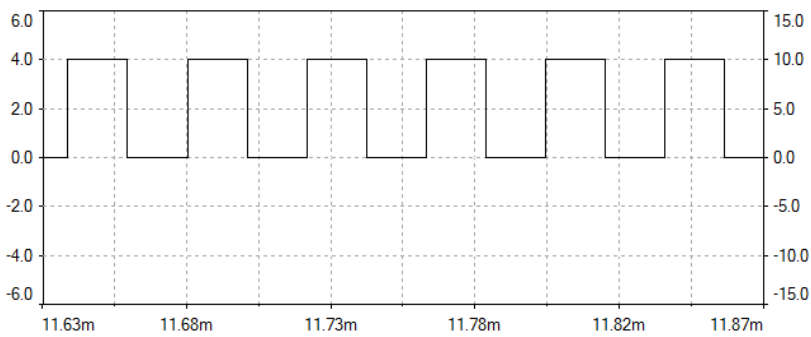

Figure 5. Voltage comparator output waveform

\section{B. Resonant Process}

By the load characteristics of the circuit analysis shows, as the temperature increases, the change of the support material, the natural resonant frequency of the load change. When the state of the inverter circuit in the open-loop, the state of the inverter circuit in the open-loop, since the switching frequency is deviated from the natural resonant frequency of the load, so that power can not operate in the power factor is equal to or close to the resonant or quasi-resonant state of the state 1 , and then the output power below standard. It must operate in a closed loop state, automatic tracking frequency[3].

Figure 6 is a frequency control circuit, a reference voltage of CPU into the reverse side of amplifying circuit(1). Its magnification :

$$
A_{\mathrm{u}}=-\frac{R_{14}}{R_{13}}
$$

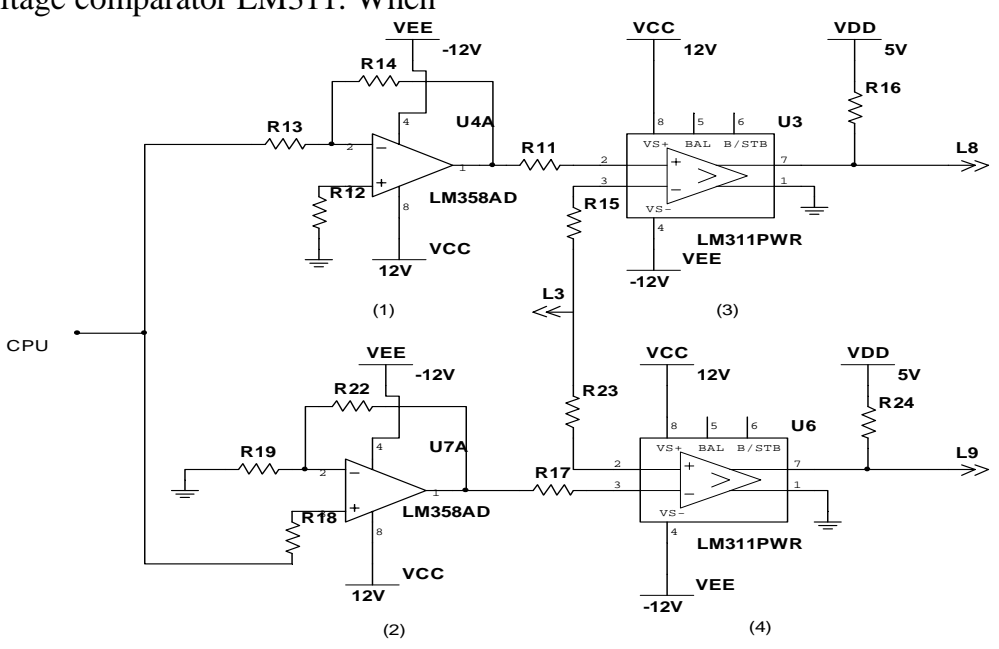

Figure 6. Frequency control circuit

An amplified negative voltage signal, this signal is input to a voltage comparator (3) of the same phase ends.
While the amplified sine wave in Figure 4 via L3 a voltage input to the comparator (3) of the inverting terminal. (a) of 
Figure 8 will be obtained (2) signal in Figure 9; From the reference voltage signal to the CPU at the same time into the amplifying circuit (2).Its magnification :

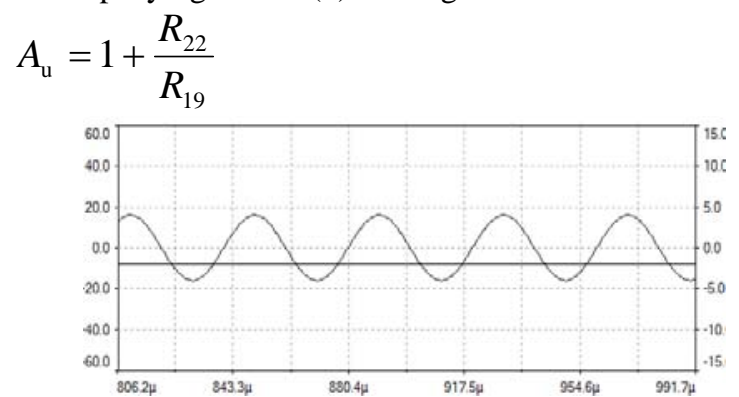

(a)

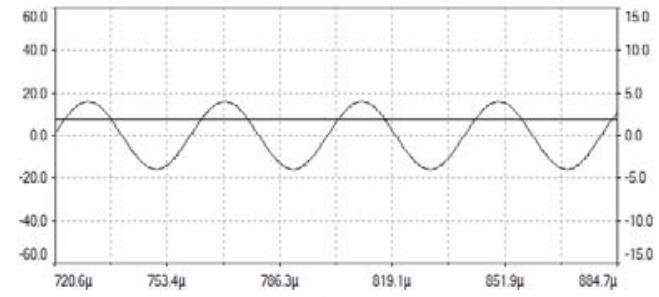

(b)

Figure 7. Voltage comparator input signal

An amplified positive voltage signal, this signal is input to the voltage comparator (4) of the inverting terminal, while the amplified sine wave in Figure 4 via $L_{3}$ a voltage input to the comparator (3) of the inverting terminal, (b) of Figure 7 will be obtained (1) the signal in Figure 8; Figure 8 (1), (2) the two signals and the current signals of the same frequency, the same phase in Figure 2. The two square-wave signals through $\mathrm{L}_{8}, \mathrm{~L}_{9}$ are input to the switch driving circuit as a drive signal[4]. The resonant frequency of the switching tube catheter frequency $f$ and the output sine wave signal coincides $f_{0}$.

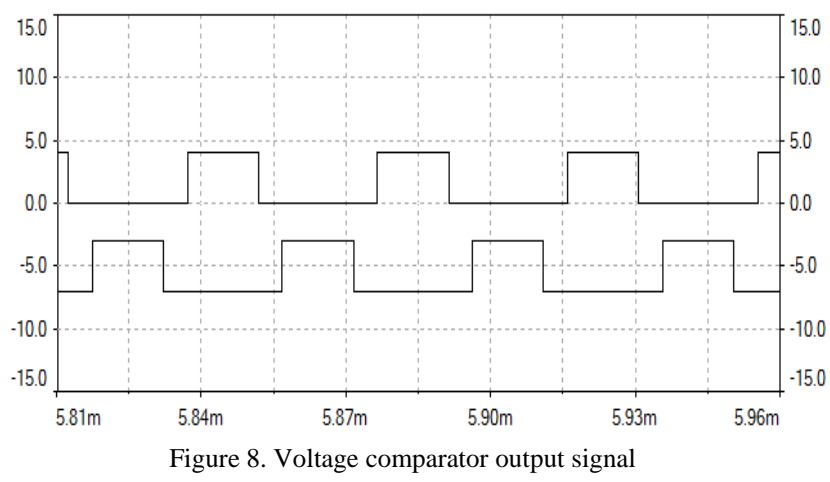

\section{Power Start}

High frequency induction heating power supply work to be done before the normal start-up resonant circuit, at this point system does not start but entered the detection status. Issued narrow pulse drive signal control the switch drive circuit to the inverter conduction, in this case the output of the inverter circuit in the load to obtain a sine wave oscillation damping. Figure 9 is a narrow pulse driving signal waveform obtained by several cycles.

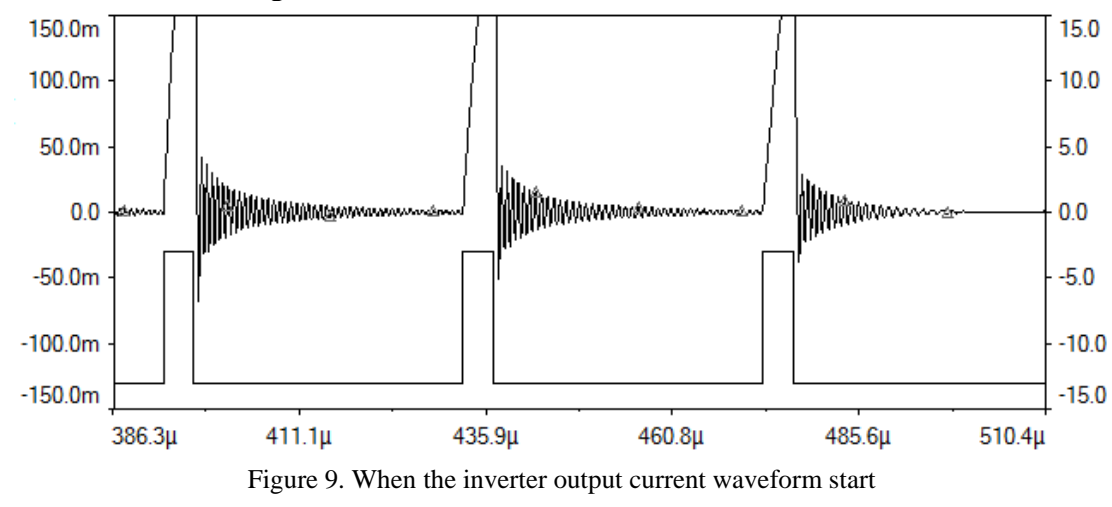

After several cycles of the system sends a short pulse signal, immediately stop sending, the resulting damped sinusoidal oscillations in the circuit through the series current transformer samples the input to the frequency analyzer circuit. After the differential amplifier circuit and a voltage comparator circuit, the resulting method in Figure 9 sine wave signals to the control system with the frequency of the microcontroller in AD. SCM identifies signal rising and low, after calculating the square wave period, issued a PWM drive signal to the driver circuit by microcontroller DA, so that the inverter circuit can operate normally[5].

\section{Experimental Results}

In order to verify the correctness of the analysis of the above theory, the designed circuit was simulated and built a prototype of $25 \mathrm{kHz} / 5 \mathrm{~kW}$.

Figure 10 is a frequency tracking simulation map in saber software. Wherein the voltage waveform is a square wave output from the inverter, sine wave is the load current waveform. Be seen from Fig.10, In the moments before one, the operating frequency of the inverter and the resonance frequency of the same; In one moment, changes the resonance frequency of the load. In two moments, has 
been completed the resonant frequency tracking. Voltage, current, a smooth transition.

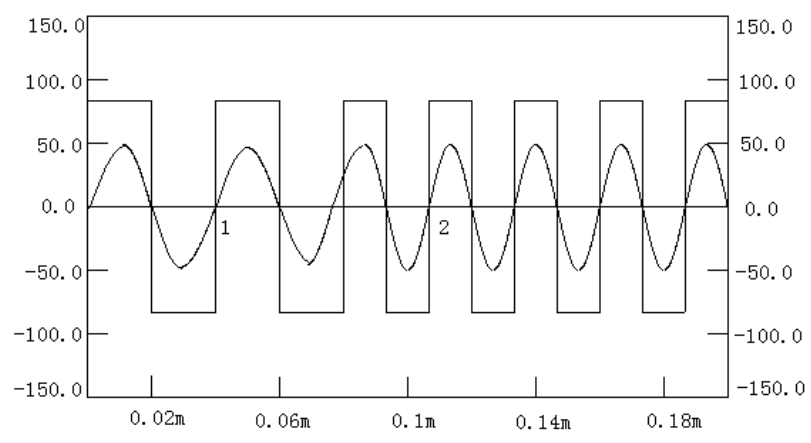

Figure 10. Frequency tracking simulation map

\section{SUMMARY}

The proposed power-up approach - narrow pulse excitation method, it can be well applied to the resonant circuit power-up. The new frequency analysis tracking circuit for high frequency induction heating power supply, analog components uses fewer in control circuit, reducing the switching time of electronic devices, it can accurately and rapidly automatic tracking frequency, to overcome the traditional circuit-track narrow frequency range, the disadvantage of the different frequency bands require different parameters of the filter network. Finally produced a prototype, through on-site commissioning prove the correctness of the theory.

\section{ACKNOWLEDGEMENTS}

This work was supported by The Jilin Province Science and Technology Development Funds Projects(20130102027JC).

\section{CORRESPONDING AUTHOR}

Yemao Zhang, 3552664@163.com,

$(+86) 15044230910$

\section{REFERENCES}

[1] Li Hong.He Yuyao.Wang Chongwu: A New Method of Frequency Tracking and Output Power Control for Full Bridge Series Load Resonant Inverter ,Transactions of China Electrotechnical Society, 93-99(2010)

[2] Yang Zongpu: Research on frequency-tracking control for induction heating power supply, Chinese Journal of Power Sources, 1296-1298(2010)

[3] Li Jingang: Implementation of Ultra-audio Frequency-tracking Control for Induction Heating Power Supply based on DSP, Power Electronics Synopsis, 16-98(2011)

[4] Li Shifeng, Lv Moying: A Novel Hybrid Full-Bridge Inverter for Ultra-High Frequency Induction Heating Applications, Transactions of China Electrotechnical Society, 215-221(2013)

[5] Kifune H, Hatanaka Y, Nakaoka M: Cost-effective phase-shifted pulse modulation soft switching high-frequency inverter for induction heating applications,IEE Proc. Electr. Power Appl.19-25(2004) 